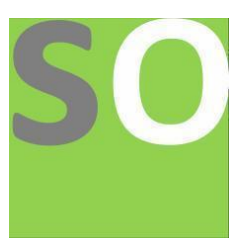

Article title: Examining the Lead Exposure and its Effects among U.S Children

Authors: Muse Abdi[1]

Affiliations: Saint Mary's University of Minnesota School of Public Health[1]

Orcid ids: 0000-0001-5892-8854[1]

Contact e-mail: fagise5147@ampswipe.com

License information: This work has been published open access under Creative Commons Attribution License $\mathrm{http}: / / c r e a t i v e c o m m o n s . o r g / l i c e n s e s / b y / 4.0 /$, which permits unrestricted use, distribution, and reproduction in any medium, provided the original work is properly cited. Conditions, terms of use and publishing policy can be found at https://www.scienceopen.com/.

Preprint statement: This article is a preprint and has not been peer-reviewed, under consideration and submitted to ScienceOpen Preprints for open peer review.

DOI: 10.14293/S2199-1006.1.SOR-.PPKVIMD.v1

Preprint first posted online: 23 August 2021

Keywords: Lead Exposure, U.S Children, Lead toxicity, Disease Surveillance, Exposure Monitoring 


\title{
Examining the Lead Exposure and its Effects among U.S Children
}

\author{
Muse Abdi \\ Saint Mary's University of Minnesota
}

School of Public Health 


\section{Problem Formulation}

According to the United States Environmental Protection Agency (2019), lead is an element that is naturally found on the surface of the earth. Lead is also harmful to humans, especially young children. Similarly, the CDC (2021) has reported that lead naturally occurs in the environment such as soil, air, and water. However, it is also commonly found in older homes. This is especially true with lower socioeconomic communities' housing. Lead exposure commonly comes from old lead pipes, faucets, and plumbing fixtures. In addition to water contamination, nearly 23 million houses have lead-based paint hazards in the United States (Egan et al., 2021). Egan and his colleagues also found that there are more than 3.6 million households with children younger than six years old living in these lead-filled homes. More than 6 million housing units still have lead water pipes in the United States (Dignam et al., 2019).

\section{Host}

Young children are the most vulnerable community to lead exposure because of two major reasons. The first reason is that children have fast-growing tissues. These tissues readily absorb things in their environments. If there is lead in the soil, dust, paint, or pipes in a child's environment, they are likely to absorb it. Very young children also have a habit of putting things in their mouths. This means, for example, paint chips with lead can end up in an infant's mouth when they are left alone for just a few seconds. To this day, lead exposure continues to affect children and continues to be a public health problem in the United States (Wheeler et al., 2021). Although there are many regulations attempting to prevent lead poisoning, lead exposure among children is the most preventable disease in the United States (Moody \& Pigozzi, 2016). Childhood lead exposure is associated with neurological and neurobehavioral deficits, slowed 
growth, anemia, reduced brain gray matter volume, and motor skill inabilities (Cecil et al., 2008).

Lead poisoning may also cause neurotoxic effects in children, resulting in long-term lower IQ, inattentiveness, and other behavioral problems (Seifu et al., 2020). In addition, according to the United States EPA (2019), lead is more dangerous to young children because it causes neurobehavioral deficits in cognition, motor abilities, and brain development.

\section{Agent}

Lead exposure is one of the most common and well-known direct and indirect environmental diseases among children in the United States. The dust in older housing and leadbased paint is one of the primary sources of lead exposure among U.S children (Egan et al., 2021). Consumer products such as imported foods as well as lead exposure in the workplace are the other common sources of lead exposure (Ettinger et al., 2019). Some occupations with possible lead exposure include working with batteries, recycling, and smelting. A parent's exposure at these workplaces can affect the children at home because parents carry lead particles on their clothes, shoes, and other items that they may bring with them. Primarily, children usually get exposed to lead by ingesting contaminated dust or soil. This lead-contaminated dust and soil usually originates from lead paint (Moody et al.,2016). Drinking water is another major source of lead exposure, especially in low socioeconomic children, because of the old infrastructure (Hanna-Attisha et al., 2016). The children can get exposed to lead through inhalation of air pollution, lead dust, and other pollutants. Specks of dust from lead-contaminated houses are the primary root causes of lead exposure among children (Lanphear et al., 1996). 


\section{Environmental Risk Factors}

There are several persistent risk factors that are behind the higher prevalence of blood lead levels in U.S children. Although blood lead levels dramatically decreased in children in the U.S over the past 40 years, minority children with low socioeconomic status have higher blood lead levels of more than non-minority children (Egan et al., 2021). Egan and his colleagues found that Black and Hispanic children have higher blood lead level prevalence when compared to white children and those from higher-income families. Similarly, lead exposure disproportionately affects African American children in the U.S. who have the highest blood lead levels of all demographics (Yeter et al., 2020)

According to the CDC (2021), children who live below the federal poverty level, those who have lower socioeconomic statuses and those who live in houses built before 1978 have higher vulnerabilities to lead exposure. The other factors that contribute to this problem are race/ethnicity, poverty, and older housing. Moody et al. (2016) found that children who have lower socioeconomic statuses and minority communities have higher rates of childhood lead exposure. Likewise, Seifu et al. (2020) reported that low socioeconomic status is a major risk factor that drives the elevated blood lead levels in U.S children. Egan et al. (2021) also suggested that sociodemographic characteristics such as income level and housing are the other factors that drive the higher prevalence of blood lead levels in U.S children.

Similarly, Seifu et al. (2020) reported, after analyzing the blood of 301 foreign-born refugee children in the U.S, that foreign-born refugee children have higher elevated blood lead levels. The average of elevated blood levels of the foreign-born refugee children upon arrival was $9 \mu \mathrm{g} / \mathrm{dL}$ with a range from 5 to $27 \mu \mathrm{g} / \mathrm{dL}$ (Seitu et al., 2020). The reason why foreign-born children have higher blood lead levels can be the low socioeconomic status of their country. 
Therefore, I believe socioeconomic status can be the primary cause of elevated blood lead levels among children.

\section{Risk Characterization}

\section{Toxicity Assessment}

According to the CDC (2021), there are no safe blood lead levels, and even trace amounts of lead in the blood can be harmful to children's health. Sachdeva et al. (2018) reported that lead toxicity is not well diagnosed since patients are usually asymptomatic. Moreover, there is no known level of lead that is not toxic to the body. Even though no known blood lead cut off point exists, blood lead levels of 5-9 $\mu \mathrm{g} / \mathrm{dL}$ are the levels at which the CDC recommends an immediate public health action. According to Sachdeva and his colleagues, $70 \%$ of lead is deposited in children's bones and teeth, which can then be released into the bloodstream.

Lead toxicity causes various pathophysiological effects in children, including oxidative stress, hematological changes, and effects on the kidneys and heart. The major pathological mechanism resulting from lead poisoning is oxidative stress, which occurs when the body's ability to compensate is overturned, resulting in cellular damage (Sachdeva et al., 2018).

Reactive oxygen species (ROS) such as hydrogen peroxide cause cellular damage by exhausting the antioxidant system, which detoxifies the excess ROS. Lead toxicity also causes hematological changes, such as red blood cells becoming fragile and their cell membranes being damaged, causing the cellular function to be disrupted, resulting in an imbalance of substance moving in and out of the cell (Sachdeva et al., 2018). According to Sachdeva and his colleagues, even minor lead exposure can cause chronic kidney failure, resulting in glycosuria (excess sugar in the urine) and aminoaciduria (an abnormal number of amino acids in the urine). 
Cardiovascular effects of lead toxicity include hypertension and other cardiovascular diseases (Sachdeva et al., 2018).

However, lead poisoning on the human body is not limited to the effects mentioned above; lead poisoning can affect any organ of the body and any level of the organ's systems. For example, as discussed in detail in the problem formulation, one of the major effects of lead poisoning on children's bodies is neurobehavioral effects, motor inabilities, low I.Q., growth retardation, inattentiveness, and other neurobehavioral effects are examples. In addition, despite limited research studies, Sachdeva et al. (2018) reported that lead toxicity could even cause human cancers, implying that lead poisoning is more dangerous than previously thought.

\section{Disease Surveillance}

There are numerous methods for measuring lead in tissues such as plasma, urine, bone, and teeth. However, blood lead concentration is one of the most commonly used methods for determining blood lead levels (National Research Council (U.S.), 1993). The level of lead in the blood is measured in micrograms per deciliter of blood $(\mu \mathrm{g} / \mathrm{dL})$. In the United States, the prevalence of lead exposure and lead poisoning has decreased; however, the number of cases remains alarming. Thirty-four states and the District of Columbia reported a total of 24,000 children with blood lead levels greater than or equal to $10 \mu \mathrm{g} / \mathrm{dL}$, as well as 243,000 children with blood lead levels greater than or equal to $5 \mu \mathrm{g} / \mathrm{dL}$ (Raymond et al., 2014). In 2010, 24,546 children aged 1 to 5 years had blood lead levels greater than $10 \mu \mathrm{g} / \mathrm{dL}$, while 19,915 children aged 1 to 5 years had blood lead levels greater than or equal to $10 \mu \mathrm{g} / \mathrm{dL}$. (Raymond et al., 2014).

Lanphear et al. (1996) reported a random sample survey used to assess the relationship between lead-contaminated house dust and blood lead levels in urban children aged 12 to 31 
months who lived in the same house for at least 6 months. The children's mean blood lead level was $7.7 \mu \mathrm{g} / \mathrm{dL}$. After controlling for other significant covariates, the estimated percentages of children with blood lead levels at or above $10 \mu \mathrm{g} / \mathrm{dL}$ were $4 \%, 15 \%$, and $20 \%$, respectively. Thus, lead-contaminated house dust was a significant contributor to lead intake among urban children with low-level blood lead elevations. This means that a significant proportion of children may have blood lead levels of at least $10 \mu \mathrm{g} / \mathrm{dL}$ at dust lead levels significantly lower than current standards. (Lanphear et al., 1996).

According to the Centers for Disease Control and Prevention's (CDC) Advisory Committee on Childhood Lead Poisoning Prevention, 74,110 children under the age of five had high blood lead levels of 5- $9 \mu \mathrm{g} / \mathrm{dL}$ in 2013. In the same year, more than 8,230 children under the age of five were found to have blood lead levels of $10 \mu \mathrm{g} / \mathrm{dL}$ (Adefis et al., 2020). Although lead-based paints were banned decades ago, children in the United States still face a risk of lead exposure. According to the National Poisoning Data System (NPDS) of the American Association of Poison Control Centers (AAPCC), 2497 lead exposures in children younger than 6 years occurred in 2019, demonstrating how lead exposure remains a public health concern for children in the United States. In addition, Adefis et al. (2020) estimated that 4 million children in the United States are exposed to lead. According to Dewalt et al. (2015), lead-based paint hazards exist in 23.2 million homes in the United States. Dewalt and his colleagues also estimated that 37.1 million homes contain lead-based paint in some form.

\section{Exposure Assessment}

Lead can enter the human body through inhalation and then spread throughout the body once it reaches the lungs. It can also enter the body through ingestion, such as when a person drinks or eats foods contaminated with lead. The time it takes for lead to be absorbed by the body, on the 
other hand, is dependent on the concentration of lead in the dust; however, it is thought that lead takes six months to raise blood lead levels and become a concern in young children. Since children often use their hands to eat, they are more likely to ingest lead from their environment. Children inhale contaminated dust particles from lead-painted woods and batteries that are being burned. Children can also be exposed to lead through lead deposited in the soil due to industrial air pollution. Most children are exposed to lead through dust contaminated with lead and paint chips from lead-based paints (Hauptman et al., 2017). Acute lead poisoning occurs when leadcontaminated particles are exposed for only a short period. In contrast, chronic lead poisoning occurs when lead-contaminated particles are exposed for a long period.

Although lead is no longer used in household products, it is still used in hunting and shooting equipment. When a hunter kills an animal, the carcasses decompose into the surrounding environment (Arnemo et al., 2016). Rainwater washes the lead in the animal carcasses into the water stream, posing a threat to the environment as a whole (Arnemo et al., 2016). The lead stored in the carcasses enters the food chain, causing lead poisoning in wildlife and agriculture (Trinogga et al., 2019). Lead can then enter the human body through contaminated agricultural products. Additionally, people who eat game-shot animals may be exposed to lead ammunition (Buenz et al., 2018). Lead can be absorbed into the leaves of plants when they are exposed to it.

\section{Exposure Monitoring}

The lead concentration in whole blood is one of the most important biomarkers in the body used for measuring lead. The federal government usually regulates blood lead levels. The lead concentration in whole blood (BPB) is the primary biomarker used to determine blood lead levels (Barbosa et al., 2005). This biomarker increases as the amount of lead in the blood increases. 
Lead levels in blood, bone, and urine are biomarkers of exposure, according to the Toxicological Profile for Lead (2020). Furthermore, the federal government designs and implements regulations, and some of the federal agencies that monitor and regulate lead poisoning are the Environmental Protection Agency (EPA), Consumer Product Safety Commission (CPSC), Occupational Safety and Health Administration (OSHA), and the Department of Agriculture (USDA), the Department of Housing and Urban Development (HUD), and the Department of Health \& Human Services (HHS).

The surveillance data on blood lead levels is easily accessible, and well-managed. The CDC is committed to tracking the progress of childhood lead exposure using available data and providing statistics to track the improvements towards its elimination (CDC, 2020). The Centers for Disease Control and Prevention (CDC) collaborates with the Council of State and Territorial Epidemiologists (CSTE) to conduct collective surveillance to monitor blood lead levels in children in the United States (CDC, 2020). According to the Centers for Disease Control and Prevention (CDC), the National Health and Nutrition Examination Survey (NHANES) is an excellent source of national biomonitoring data for lead. In addition, the Healthy Homes and Lead Poisoning Surveillance System (HHLPSS) is another data platform for data storage and management of blood lead levels in children in the United States. Another primary source of blood lead surveillance data at the state level is the Childhood Lead Poisoning Prevention Program (CLPPP).

\section{Ecological Impacts}

Lead air pollution can accumulate in the environment, causing environmental damage. When lead enters the environment, it eventually ends up in the air, water, and soil. This contributes to pollution, especially in urban areas (US EPA, n.d). The major causes of ecological impacts, 
according to the US EPA (2019), are waste streams discharged into water bodies and mining. In addition, reduced plant growth and reproduction as well as neurological effects in vertebrates are contributors of lead on the ecosystem, wildlife, and agriculture (EPA, n.d). In this case, lead can spread and impact the environment in a variety of ways. As a result, the best solution for controlling this dangerous toxic element is prevention.

\section{Risk Management}

\section{Community Organizations}

Many community organizations deal with childhood lead poisoning across the United States. The National Center for Healthy Housing (NCHH), National Safe and Healthy Housing Coalition, and Green \& Healthy Homes Initiative (GHHI) stand out with their exceptional work on childhood lead poisoning prevention. In general, these organizations conduct scientific research and identify the best evidence-based practices that provide safe and effective ways to solve childhood lead poisoning (Healthy Housing Solutions [HHS], n.d). In addition, they provide tools and resources for the communities to effectively communicate their home-related problems, especially lead exposure, to government agencies (NCHH, n.d). Furthermore, these organizations provide discussion platforms in order to develop exclusive efforts about how to have healthy and safe housing and increase the awareness in the communities about childhood lead poisoning. These organizations provide resources and tools about how to get rid of the barriers around getting healthy and safe housing $(\mathrm{NCHH})$.

One intervention is to increase the capacity of healthy and safe housing. NCHH has improved the capacity of the systems at local, state, and federal levels to provide safe and healthy housing for these communities (NCHH, n.d). Again, it increased the awareness of the 
community members about getting healthy and safe housing. To obtain effective results, $\mathrm{NCHH}$ hires qualified scientists who conduct in-depth research and provide science-based evidence to get solutions for getting healthy and safe housing to prevent childhood lead poisoning and other housing-related environmental health problems $(\mathrm{NCHH}) . \mathrm{NCHH}$ then converts this researched evidence into a practical experience that is utilized by the local, state, and federal levels and other public health experts including healthcare providers (HHS, n.d).

One specific strategy by $\mathrm{NCHH}$ and the National Safe and Healthy Housing Coalition, called "Find It, Fix It, Fund It" has more than 150 growing members. This program is intended to eliminate lead poisoning hazards while providing lead surveillance and home follow-up services to eliminate lead poisoning hazards $(\mathrm{NCHH}, 2016)$. This program also supports other allies and partners who are part of the fight against lead poisoning hazards. NCHH campaigned to increase the funding and improvement of HUD's Office of Lead Hazard Control and Healthy Homes, CDC's Healthy Homes and Lead Poisoning Prevention Program, home-based lead follow-up services, lead-based risk assessments, and HUD inspection protocols (NCHH, 2016). This program made more than 50 recommendations on lead poisoning prevention to federal agencies, including the congress (NCHH, 2016). Recently, NCHH conducted Appropriations, Administrative Advocacy, Legislative Advocacy, National Safe and Healthy Housing Coalition Advocacy, and Media Advocacy for childhood lead poisoning elimination at federal level sectors such as the legislative and executive branches (NCHH, 2016).

Furthermore, the Green and Healthy Homes Initiative (GHHI) links resources from the public and government sectors to create policies to overcome barriers around the elimination of lead poisoning hazards. The organization designed and implemented the Lead Hazard Reduction program which works on preventing childhood lead poisoning. GHHI advocated childhood lead 
poisoning prevention policies and attended numerous conferences including conferences in the White House, the Department of Housing and Urban Development (HUD), and the U.S Conference of Mayors. In 2021, GHHI proposed a new bill called the "Environmental Justice Legacy Pollution Cleanup Act” which was co-sponsored by Senator Cory Booker and Congressman Donald McEachin (NCHH, n.d). GHHI designed this proposed federal legislation to stop the racial and environmental injustice in the U.S, with $\$ 45$ billion going to lead hazard remediation while another $\$ 45$ billion is for lead paint service replacement (NCHH, n.d).

These above-mentioned organizations have many partners and collaborators. For example, the well-known program "Find It, Fix It, Fund It" designed and implemented by $\mathrm{NCHH}$, has a partnership called "Action Drive Members" (NCHH, n.d). Some of the members of these partnerships are the National Safe and Healthy Housing Coalition, National Center for Healthy Housing, Coalition to Prevent Lead Poisoning, Green \& Healthy Homes Initiative, WHO, etc. These are just a few examples of the many partners of this collective action.

The progress or success of these organizational efforts can be measured by the number of actions that have been taken and their impacts on childhood lead poisoning hazards. For instance, these efforts made possible the passing of $\$ 25$ million in lead hazard control funding by the U.S. Senate Appropriations Committee in 2016 (NCHH, 2016). In that same year, NCHH and its collaborators worked with 20 senators and hundreds of other organizations to secure $\$ 230$ million for lead hazard control and healthy homes for HUD (NCHH, 2016). Also in 2016, these efforts advocated HUD for its largest housing program, Section 8, to protect the health and safety of its recipients of the section 8 vouchers and convinced the HUD to upgrade its housing quality standards (NCHH, 2016). NCHH and its partners worked with over 75 U.S representatives and established the CDC's Childhood Lead Poisoning Prevention Program (CLPPP), which is an 
important program in preventing childhood lead poisoning hazards (NCHH, 2019). NCHH and other community organizations provided technical assistance and scientific advice to members of congress and passed six lead poisoning prevention bills in 2016 alone (NCHH, 2016).

These mentioned organizations are funded by many individuals, private foundations, and corporations. For example, some of the prominent donors of these organizations are Abell Foundation, American Public Health Association, Archstone Foundation, and more. (NCHH, n.d). However, there are limitations in the funding of these community organizations. They have limited funding, especially since they may not receive government funding on top of the private donors. Therefore, the funding they receive is often less than what is needed to fund the services they provide.

\section{Recommendations}

The exposures to lead hazards disproportionately impact children of color and children from low-income families. Until this aspect of lead exposure is addressed, all of the efforts that are being made will fall short of their ultimate goal. The environmental justice, socioeconomic status, and ethnicity problems are core foundations of why America has failed to solve this totally preventable environmental health problem (Kerpelman et al., 2020). There are tens of millions of homes that have lead paint in the U.S, and they pose a threat of irreversible damage to children (Kerpelman et al., 2020). In addition, landlords and sellers often refuse to eliminate lead paint or even test for it on their properties, and the government agencies fail to design and implement effective laws and enforceable regulations (Kerpelman et al., 2020). While not directly stated, the data can be used to make a case for the fact that the reason why America ignored this totally preventable public health problem is that lead poisoning affects children of 
color and low-income children. Therefore, the current policies and regulations are not working for children of color and children with a lower socioeconomic status. In addition, Kerpelman et al. (2020) said that the current state laws have failed to address this unfortunate environmental public health crisis. Racial and economic discrimination can be the primary drivers of why the government levels do not resolve this easily preventable public and environmental health problem (Kerpelman et al., 2020). Furthermore, Kerpelmal et al. argued that childhood lead poisoning is a denial of constitutional and civil rights.

Some states have policies on childhood lead screening, but thus screening is not conducted regularly; therefore, the best policy option should be designing and implementing new state laws mandating monthly childhood blood lead testing and regular home-based follow-up lead services which are legally enacted. States should also monitor how the healthcare system performs the screening of children's blood lead screening and should provide home-based-up services to ensure that the children are getting blood lead screening and living in healthy and safe houses. The states should produce laws that eliminate the lead paint of older houses which are mostly lived in by minority and low-income children. Also, the states should develop and implement policies that monitor whether contractors follow the rules and regulations of the Environmental Protection Agency. In addition, the states could provide adequate parental education on environmental household interventions to reduce the lead exposure such as removal of lead dust or home remediation work (Nussbaumer-Streit et al., 2020).

Federal laws that can provide oversight of the state laws could be the ultimate solutions for this unfortunate ongoing environmental injustice. Since this issue is constitutional and civil rights, the best solution is to pass effective federal laws and force the states to enforce these laws. These laws will require the states to develop effective policies and regulations mandating 
monthly inspections of rental apartments and other residentials that are lived by the communities of color and low-income communities. However, these would require the landlords and sellers to eliminate lead hazards from their properties. Furthermore, local, state, and federal agencies should take their constitutional responsibilities seriously and enact effective policies and regulations on lead poisoning and not only that they must enforce these policies and regulations; otherwise, like what is happening now, if all levels of the government do not enforce these policies and regulations, the landlords and sellers may not remove lead hazards from their properties. Therefore, effective enacted laws and enforced regulations are needed, and more importantly, enforcement is the most crucial action needed because the current state laws and regulations have failed because of lack of enforcement (Kerpelmal et al., 2020).

Childhood lead poisoning hazards need effective policies and regulations that are enforced; otherwise, these above-mentioned organizational efforts are temporary and not permanent solutions. However, the states should update their policies and make sure that childhood lead screening is available to any child regardless of economic status or location. The key types of legislation needed to prevent lead-poisoning are

1) Laws that create penalties for hazardous materials

2) Laws the create incentives for landlords to remove paint

3) Laws that create uniform testing and monitoring services

4) Laws the allocate funding for the removal of lead hazards

In addition, the nonprofit community organizations and the community leaders should step up and demand their constitutional and civil rights from their elected officials; otherwise, the suffering of children of color and the children from low-income families will continue and pass to the next generations. However, the community organizations mostly depend on 
individual and other community funders, but these little resources are not meeting the needs of actions of lead poisoning.

The communities should organize themselves and call on their elected officials and pressure them to pass effective laws and regulations against lead poisoning hazards and then enforce these laws and regulations. Also, the communities should put more pressure on the landlords, sellers, and contractors to eliminate lead poisoning hazards from their properties. Similarly, renters should call for independent lead inspectors and demand their units should be tested for lead exposure before moving in. In addition, the communities should take their role and prevent childhood lead poisoning by taking all the necessary preventive measures. The household members should clean their houses or rental units on a weekly basis to eliminate entryway floor lead-dust from outside (Dignam et al., 2019). They should also keep shoes out of reach of children, because shoes from outside can harbor lead-contaminated soil.

It is important to consider the needs of landlords, especially those with only a few units, and low-income property owners. These regulations and penalties should be designed to provide resources and minimize the hardship on low-income communities. Any penalties, in the interest of equity, should be sliding scale and those who cannot afford lead abatement should be given subsidies in the form of direct payments to licensed contractors or tax subsidies. The cost of lead removal is considerable, and it is imperative that solutions to lead-poisoning prevention not prove a further burden to the very communities most impacted by lead contamination.

Several resources are needed to implement the proposed action, and they should come from both the state and federal governments. The state and federal governments should allocate a budget to implement the proposed action. If the federal government provides enough resources to 
the states and the states provide enough resources to lead poisoning prevention programs, childhood lead poisoning is $100 \%$ preventable and needs enough resources, effective laws, and honest enforcement (CDC, 2019). These resources will make possible localized preventive programs that can conduct both primary and secondary prevention. For example, if the levels of the government provide enough resources, the above-proposed actions can conduct primary prevention by eliminating environmental hazards before the children get exposed to them. In addition to that, if the levels of the government provide enough human and financial resources, the above-proposed action can expand the existing local secondary prevention by ensuring that every child gets monthly blood lead testing and follow-up services.

The funding for these programs should come from fines imposed on landlords with more than 10 properties if they fail to implement abatement strategies and from landlord licensing fees. These funds can be used as both a carrot and a stick. The fines will incentivize compliance for those most able to afford abatement, while providing funds to those least able to afford it. Additional funding could come from fines and taxes levied against corporate lead producers such as battery manufactures or lead ammunition manufacturers. Adding enforcement actions and substantial fines would encourage good behavior while also providing funds to abate the lead pollution that already exists.

\section{Conclusion}

Levels of lead poisoning in the United States of America continue to fall year after year. However, there is a dangerous amount of minority and low socioeconomic children that are still exposed to dangerous levels of lead every day. Whether it be infants ingesting lead paint chips, dangerous air pollutants or lead sources brought into the home, these kids are in danger. 
While there have been many attempts over the years to tackle the problem of lead poisoning, especially in children, many of those attempts fall short. One of the major reasons why those attempts fall short is the lack of money being spent on these at-risk communities. Many laws and policies are only implemented in new construction or in areas that can afford to replace dangerous lead containing hazards. Poor and minority communities are often left without the resources to remove these hazards and even when laws exist, they are often not enforced against landlords or sellers.

Lead poisoning is a relatively simple issue to tackle, as once these hazards have been removed, they are gone forever. It would take a large undertaking of local, state, and federal agencies, creating and enforcing laws and financial opportunities to remove these dangers. This cost is greatly outweighed by the fact that it will cause a reduction in children being exposed to lead poisoning for generations to come. This means that the local, state, and federal governments will not only save millions of dollars in health care costs, but our children will be able to live and breathe without fear of being poisoned by the homes they are supposed to feel safe in. 


\section{References}

Adefris Adal, Sage W Wiener, Sage W Wiener, John T VanDeVoort, John T

VanDeVoort. (2020). https://www.medscape.com/answers/814960-121131/whatis-the-prevalence-of-lead-toxicity-in-the-us

Agency for Toxic Substances and Disease Registry (2020). Toxicological profile for lead agency for toxic substances and disease registry, U.S. Department of Health and Human Services. Atlanta, GA.

Alliance to End Childhood Lead Poisoning. (n.d). https://nchh.org/resourcelibrary/Another_Link_in_Chain.pdf

Arnemo, J. M., Andersen, O., Stokke, S., Thomas, V. G., Krone, O., Pain, D. J., \& Mateo, R. (2016). Health and environmental risks from lead-based ammunition: Science versus socio-politics. EcoHealth, 13(4), 618-622.

Barbosa, F., Jr, Tanus-Santos, J. E., Gerlach, R. F., \& Parsons, P. J. (2005). A critical review of biomarkers used for monitoring human exposure to lead: advantages, limitations, and future needs. Environmental Health Perspectives, 113(12), 16691674. https://doi.org/10.1289/ehp.7917

Buenz, E. J., \& Parry, G. J. (2018). Chronic lead intoxication from eating wild-harvested game. The American Journal of Medicine, 131(5), e181-e184.

CDC. (2019). Lead Poisoning Prevention.

https://www.cdc.gov/nceh/lead/prevention/default.htm\#: :text=No\%20safe\%20bl ood\%20lead\%20level,lead\%20poisoning\%20is\%20100\%25\%20preventable. 
CDC. (2020). Data and Statistics. https://www.cdc.gov/nceh/lead/data/index.htm

CDC. (2020). Populations at Higher Risk.

https://www.cdc.gov/nceh/lead/prevention/populations.htm\#: :text=For\%20exam ple $\% 2 \mathrm{C} \% 20$ older $\% 20$ houses $\% 20$ and,greatest $\% 20$ risk $\% 20$ of $\% 20$ lead $\% 20$ exposur

e.

CDC. (2021). Blood Lead Levels in Children.

https://www.cdc.gov/nceh/lead/prevention/blood-lead-levels.htm

Cecil, K. M., Brubaker, C. J., Adler, C. M., Dietrich, K. N., Altaye, M., Egelhoff, J. C., ... \& Lanphear, B. P. (2008). Decreased brain volume in adults with childhood lead exposure. PLoS Med, 5(5), e112.

Dewalt, F. G., Cox, D. C., O’Haver, R., Salatino, B., Holmes, D., Ashley, P. J., Pinzer, E. A., Friedman, W., Marker, D., Viet, S. M., \& Fraser, A. (2015). Prevalence of Lead Hazards and Soil Arsenic in U.S. Housing. Journal of Environmental Health, 78(5), 22-52.

Dignam, T., Kaufmann, R. B., LeStourgeon, L., \& Brown, M. J. (2019). Control of lead sources in the United States, 1970-2017: public health progress and current challenges to eliminating lead exposure. Journal of public health management and practice: JPHMP, 25(Suppl 1 LEAD POISONING PREVENTION), S13.

Dignam, T., Pomales, A., Werner, L., Newbern, E. C., Hodge, J., Nielsen, J., Grober, A., Scruton, K., Young, R., Kelly, J., \& Brown, M. J. (2019). Assessment of Child Lead Exposure in a Philadelphia Community, 2014. Journal of Public Health 
Management and Practice: JPHMP, 25(1), 53-61.

https://doi.org/10.1097/PHH.0000000000000711

Egan, K. B., Cornwell, C. R., Courtney, J. G., \& Ettinger, A. S. (2021). Blood Lead Levels in U.S. Children Ages 1-11 Years, 1976-2016. Environmental Health Perspectives, 129(3), 037003-1-037003-11. https://doiorg.xxproxy.smumn.edu/10.1289/EHP7932

Ettinger AS, Ruckart PZ, Dignam T. (2019). Lead poisoning prevention: the unfinished agenda. J Public Health Manag Pract 25(1): S1-S2, PMID: 30507762, https://doi.org/ 10.1097/PHH.0000000000000902.

Hanna-Attisha, M., LaChance, J., Sadler, R. C., \& Champney Schnepp, A. (2016). Elevated blood lead levels in children associated with the Flint drinking water crisis: A spatial analysis of risk and public health response. American Journal of Public Health, 106(2), 283-290.

Hauptman, M., Bruccoleri, R., \& Woolf, A. D. (2017). An Update on Childhood Lead Poisoning. Clinical Pediatric Emergency Medicine, 18(3), 181-192. https://doi.org/10.1016/j.cpem.2017.07.010

Healthy Housing Solutions, Inc. (n.d). Applied Field Research. https://healthyhousingsolutions.com/services/applied-field-research/

Kerpelman, H. (2020). Let them eat paint: Childhood lead paint poisoning as the denial of constitutional and civil rights. Columbia Human Rights Law Review, 51(2), $828-890$. 
Knott, J., Gilbert, J., Hoccom, D. G., \& Green, R. E. (2010). Implications for wildlife and humans of dietary exposure to lead from fragments of lead rifle bullets in deer shot in the U.K. Science of the Total Environment, 409(1), 95-99.

Lanphear, B. P., Weitzman, M., Winter, N. L., Eberly, S., Yakir, B., Tanner, M., ... \& Matte, T. D. (1996). Lead-contaminated house dust and urban children's blood lead levels. American Journal of Public Health, 86(10), 1416-1421.

Lanphear, B. P., Weitzman, M., Winter, N. L., Eberly, S., Yakir, B., Tanner, M., ... \& Matte, T. D. (1996). Lead-contaminated house dust and urban children's blood lead levels. American Journal of Public Health, 86(10), 1416-1421.

Moody, H. A., Darden, J. T., \& Pigozzi, B. W. (2016). The relationship of neighborhood socioeconomic differences and racial residential segregation to childhood blood lead levels in Metropolitan Detroit. Journal of Urban Health, 93(5), 820-839.

National Center for Healthy Housing. (n.d). https://nchh.org/

National Center for Healthy Housing. (n.d). Introducing Find It, Fix It, Fund It. https://nchh.org/build-the-movement/find-fix-fund/

National Research Council (U.S.) Committee on Measuring Lead in Critical Populations. (1993, January 1). Methods for Assessing Exposure to Lead. Measuring Lead Exposure in Infants, Children, and Other Sensitive Populations. https://www.ncbi.nlm.nih.gov/books/NBK236457/.

Nussbaumer-Streit, B., Mayr, V., Dobrescu, A. I., Wagner, G., Chapman, A., Pfadenhauer, L. M., ... \& Gartlehner, G. (2020). Household interventions for 
secondary prevention of domestic lead exposure in children. Cochrane Database of Systematic Reviews, (10).

Raymond, J., Wheeler, W., \& Brown, M. J. (2014). Lead Screening and Prevalence of Blood Lead Levels in Children Aged 1-2 Years -- Child Blood Lead Surveillance System, United States, 2002-2010 and National Health and Nutrition Examination Survey, United States, 1999-2010. MMWR: Morbidity \& Mortality Weekly Report, 63, 36.

Sachdeva, C., Thakur, K., Sharma, A., \& Sharma, K. K. (2018). Lead: Tiny but Mighty Poison. Indian Journal of Clinical Biochemistry: IJCB, 33(2), 132-146. https://doi-org.xxproxy.smumn.edu/10.1007/s12291-017-0680-3

Seifu, S., Tanabe, K., \& Hauck, F. R. (2020). The prevalence of elevated blood lead levels in foreign-born refugee children upon arrival to the U.S. and the adequacy of follow-up treatment. Journal of Immigrant and Minority Health, 22(1), 10-16. https://doi-org.xxproxy.smumn.edu/10.1007/s10903-019-00878-6

Trinogga, A. L., Courtiol, A., \& Krone, O. (2019). Fragmentation of lead-free and leadbased hunting rifle bullets under real life hunting conditions in Germany. Ambio, 48(9), 1056-1064.

U.S Environmental Protection Agency. (n.d). Learn about lead. https://www.epa.gov/lead/learn-about-lead

US EPA. (n.d). Basic information about lead air pollution. https://www.epa.gov/lead-airpollution/basic-information-about-lead-air-pollution 
Wheeler, D. C., Boyle, J., Raman, S., \& Nelson, E. J. (2021). Modeling elevated blood lead level risk across the United States. The Science of the Total Environment, 769, 145-237. https://doiorg.xxproxy.smumn.edu/10.1016/j.scitotenv.2021.145237

Yeter, D., Banks, E. C., \& Aschner, M. (2020). Disparity in risk factor severity for early childhood blood lead among predominantly African American black children: The 1999 to 2010 US nhanes. International Journal of Environmental Research and Public Health, 17(5). https://doiorg.xxproxy.smumn.edu/10.3390/ijerph17051552 